\title{
Impact of Relational Management and Culture on System Success Perceptions in an IT Outsourcing Project
}

\author{
Sameer Dutta ${ }^{1}$, Milton Silver ${ }^{2} \&$ Olu Omolayole ${ }^{3}$ \\ ${ }^{1}$ Assistant Professor, Division of Computing, McKendree University, Lebanon \\ ${ }^{2}$ Professor Emeritus, LeBow College of Business, Drexel University, USA \\ ${ }^{3}$ Professor, College of Business, Grambling State University, USA \\ Correspondence: Sameer Dutta, Assistant Professor, Division of Computing, McKendree University, Lebanon. \\ E-mail: sdutta@mckendree.edu
}

Received: June 2, 2017

Accepted: July 5, 2017

Online Published: July 18, 2017

doi:10.5539/ijbm.v12n8p61

URL: https://doi.org/10.5539/ijbm.v12n8p61

\begin{abstract}
This study investigates whether trust between user and vendor can lead to formation of system success perception in the mind of the user in an IT outsourcing project. Further, the impact of culture in the form of user power distance index on the relationship between trust and user system success perception is tested. Results confirm that trust can lead to formation of system success perception, however, culture in the form of user power distance index was not found to impact the relationship between trust and user system success perception.
\end{abstract}

Keywords: Culture, IT outsourcing, Power distance index, System success, Trust

\section{Introduction}

\subsection{IT Outsourcing}

Offshore outsourcing of information systems has seen considerable growth over the recent years (Dibbern, Winkler, \& Heinzl, 2008). Global expenditures on IT outsourcing were projected to reach US\$161 billion by 2007 (Gartner Research, 2007). It had reached US\$ 288 billion by 2013 (Statista.com 2015). Offshore outsourcing has gained momentum as organizations try to offset the IT costs associated with not only routine, transaction-based systems but also with complex, customized strategic systems (Carmel \& Agarwal, 2002; Rai, Maruping, \& Venkatesh, 2009). Despite its popularity IT outsourcing has been beset with a high failure rate of over $50 \%$ (Lacity \& Wilcocks 1998). According to McDougall (2006), 28\% of the outsourcing projects fail due to contractual management factors.

\section{Theoretical Background}

\subsection{Trust-Centric Relational Management}

An emerging body of research has reinforced the notion that relational management helps inter-organizational exchanges in general (McEvily, Perrone, \& Zaheer, 2003) and IT outsourcing in particular (Sabherwal, 1999). Relational management refers to the enforcement of obligations, promises, and expectations that occur through trust and social identification (Goo et al., 2009; MacNeil, 1980). According to Poppo and Zenger (2002) trust is at the core of relational management and this study also adopted the trust-centric conceptualization of relational management, specifically trust between the user and the vendor in an IT outsourcing project. That relational management relies on trust is not surprising because in a relationship between two parties trust can foster norms of flexibility, solidarity, and information exchange (Gefen et al., 2008), and in a business relationship can cover lacunas of formal contracts (Poppo \& Zenger, 2002). Thus, the relational management approach functions on the presumption that business interactions are not just discrete and sterile processes but often involve human relationship elements as well. Relational management in business transactions allows partners to limit normally expected hazards in contracting posed by asset specificity, measurement, and complexity because they are negotiated in the spirit of trust and cooperation (Goo et al., 2009, Poppo \& Zenger 2002).

IT outsourcing projects have displayed less than stellar success in the past (McDougall, 2006). Although parties to an outsourcing partnership might take all due care in designing formal contracts, the bounded rationality of the actors imposes significant information gathering and processing costs in designing complete comprehensive 
contracts (Hart, 1995; Simon, 1957; Tirole, 2007; Williamson, 1985). Given that possibilities of opportunistic behavior are always present in an IT outsourcing situation (Gefen et al., 2008), it makes relying on contractual governance mechanisms alone less effective. Historical experience guides that formal contracting by itself is not going to resolve the low success rate of outsourcing projects, therefore, trust-centric relational management can help reduce the reliance on strictly contractual governance by adding a relational element to conventional transaction cost based governance (Poppo \& Zenger, 2002). Given the centrality of trust to relational management, it is discussed in the next section.

\subsection{Trust}

According to Mayer, Davis, and Schoorman (1995), trust is one's willingness to be vulnerable to the actions of another based on the expectations that the other will perform a specific act important to the trustor. Previous research has attested to the importance of trust in business interactions. Trust among stakeholders was found to be a key success factor in outsourced IT projects (Lander, Purvis, McCray, \& Leigh, 2004; Sabherwal, 1999). Trust is also critical in business and social interactions marked by the dependency of one party on another and a lack of control over the other party (Gefen, 2004; Fukuyama, 1995; Hosmer, 1995; Mayer et al., 1995). Existence of trust, in a shared relationship, permits people to participate in uncertain activities that they cannot fully control or monitor and yet where they could suffer, as a result of the actions of others (Luhmann, 1988). Such conditions are common in IT outsourcing projects given the geographical and cultural distance between the users and the vendor and have been managed using formal contractual governance for the most part. Researchers have found that trust-based relationships, such as relational management, do help reduce the importance placed by partners on formal governance mechanisms (Rustagi et al., 2008). However, how relational management actually achieves this effect is not well understood. Inducing positive perceptions among users regarding the success potential of the project under development could be one of the reasons for a lesser reliance on formal agency-centric mechanisms in outsourcing projects. Accordingly, the present study hypothesizes that the presence of trust between the user and vendor is an indicator of relational management and is therefore expected to contribute to the user's perception of system success. Though this study acknowledges the importance of traditional formal contracting in managing an IT outsourcing-exchange process, however, one of its objective is understanding whether trust-centric relational management can influence perceptions of system success in an IT outsourcing project. Whether trust-centric relational management can influence the system-success perceptions of users in an IT outsourcing process is as an under researched area as yet. Information systems theory benefits from this added contribution.

\subsection{Cross-Cultural Issues in IT Outsourcing}

Although not all outsourcing crosses international borders, outsourcing IT projects to another country necessarily involves cross-cultural issues; therefore, this study also focused on the culture aspect in IT outsourcing. Rai et al. (2009) found that differences in cultural norms affected the success of offshore IT projects. One manifestation of cultural norms is the Power Distance Index (PDI) values of the user. Power distance was first defined by Hofstede (1980). The concept is considered to be the degree to which the members of institutions and organizations within a country expect and accept that power is not distributed equally (Ford, Connelly, \& Meister, 2003; Hofstede, 1980, 2001). The higher the PDI, the greater the acceptance by subscribers to that culture that inequality is inherent in society (Gefen \& Heart, 2006). Some examples of influence of PDI include people in a position of authority acting as powerfully as possible, people in less powerful positions accepting steep income disparities, administrators structuring the organization as a tall pyramid, and subordinates expecting to be told their responsibilities in explicit and clear terms, indicating a lack of autonomy and leverage in their actions (Hofstede, 1980).

This study employs PDI to represent the cultural dimension encapsulating an IT outsourcing project due to four key reasons. Firstly, the relationship between the client and the vendor is essentially hierarchical (Kadefors, 2004). The tendering and governing process in IT outsourcing projects entitles the entities related to the client to assess vendor and not the other way around. This introduces an implicit hierarchical equation in the client-vendor relationship (Kadefors, 2004). Hofstede (2001) stated that hierarchical relationships are better understood through the concept of power distance. Secondly, power distance (a) often determines behaviors in which the interacting parties differ in perceived power or status rankings (Hofstede, 1984) and (b) relates to situations concerned with relationship to authority (Doney et al., 1998). Thirdly, according to Doney et al. (1998), power distance falls under the category of relations with others in the taxonomy of culture described by Clark (1990). Other dimensions of culture proposed by Hofstede (1984) (e.g., individualism-collectivism, uncertainty avoidance, and masculinity-femininity) deal with perceptions of the self or relate to risk domains of culture as explained in Clark's (1990) taxonomy of culture (Doney et al., 1998). Hence, they are not expected to play an 
important part in client-vendor interactions in an IT outsourcing project. Fourthly, power distance is also particularly suitable to understanding trade relations because it affects the negotiation behavior of the contracting parties (Hofstede, Jonker, \& Verwaart, 2008). In same vein, according to Volkema (2004), power distance is negatively related to the perceived appropriateness of competitive bargaining, thus making it suitable for understanding the behavior of parties engaged in business interactions. Accordingly, PDI provides the appropriate cultural context through which to better our understanding of client-vendor interactions in the relational management of an IT outsourcing project.

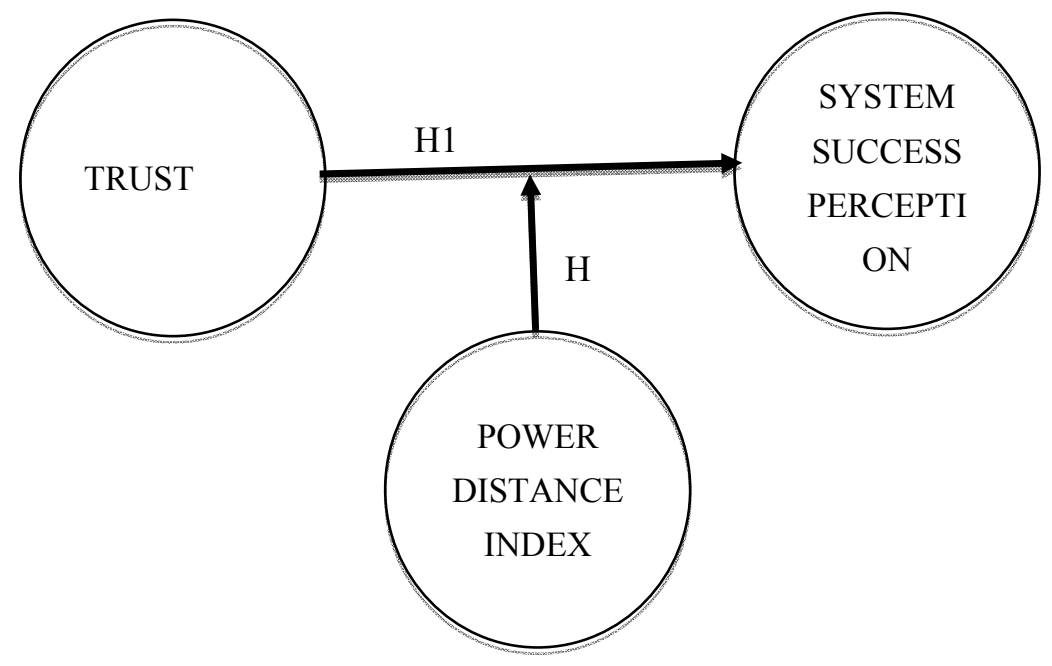

Figure 1. Study model

\subsection{Trust - PDI Interaction}

This study hypothesized that the user's power-distance values will moderate the role of trust between user and vendor on the users' system-success perceptions. According to existing research, higher PDI values are likely to reduce the importance of trust in a business relationship (Lachman, Nedd, \& Hining, 1995; Nasierowski \& Mikula, 1998), whereas low PDI values are likely to make trust an important element of the business relationship (Hofstede, 2001). Therefore, user subscribing to high power-distance values is less likely to believe in the efficacy of participative trust-based relationship and more likely to believe in the hierarchical, control-based relationship (Lachman et al., 1995; Nasierowski, \& Mikula, 1998). From high power-distance perspective, the powerful dictate the conditions (Hofstede et al., 2008); hence, trust loses its centrality in the relationship to power. According to Hofstede $(1980,1984)$, in a high power-distance culture, the legitimacy of power is irrelevant-power is exercised for its own sake. Relationships are based on an exercise of power, whether justified or not. Accordingly, for a subscriber to high power-distance culture, trust is not likely to be as important as power. A high power-distance user is not going to put much faith in the vendor performing better simply because the client encouraged a trust-based cooperative relationship with the vendor. A high power-distance user is more likely to believe in projecting power to ensure superior vendor performance. Relational management of an outsourcing project is not likely to substantially enhance a high power-distance user's perceptions of system success because it lacks the element of power.

On the other hand, a user subscribing to low power-distance values is more likely to believe in the harmony between the more powerful and less powerful (Hofstede, 2001). A user subscribing to low power-distance values is less likely to expect that the partner will engage in unethical behavior (Gefen \& Heart, 2006; Shaffer \& O'Hara 1995). Thus, a user with low power-distance values is likely to rely more on trust than exercise of power in his or her relationship with the vendor compared to a user with high power-distance values (Gefen, \& Heart, 2006; Shaffer \& O'Hara, 1995). Accordingly, for users with low power-distance values, the presence of trust toward the vendor is more likely to play a prominent part in the formation of system-success perceptions.

The impact of PDI values on user-client interaction goes against the currently prevailing view in the IT outsourcing literature that relational management will produce positive perceptions in most instances. Perception of relational management's efficacy is likely to be affected by the cultural context in which the user is embedded. Therefore, studies investigating the impact of relational management on project performance need to pay more attention to cultural factors affecting the project environment. 
Accordingly,

- In situation of high PDI, trust between the user and the vendor is less likely to lead to the formation of user's system-success perceptions as compared to low power-distance situation.

- In situation of low PDI, trust between the user and the vendor is more likely to lead to the formation of user's system-success perceptions as compared to situation of high PDI.

In situations of high PDI, trust is not likely to be very important to the user; however, in situations of low PDI, trust is likely to have a greater impact on the user's system-success perceptions. This aspect of the investigation is important because trust centric relational management of an outsourcing project is normally supposed to improve interaction between the two parties. However, the effect of trust on the user's system-success perceptions is likely to be moderated by the user's PDI.

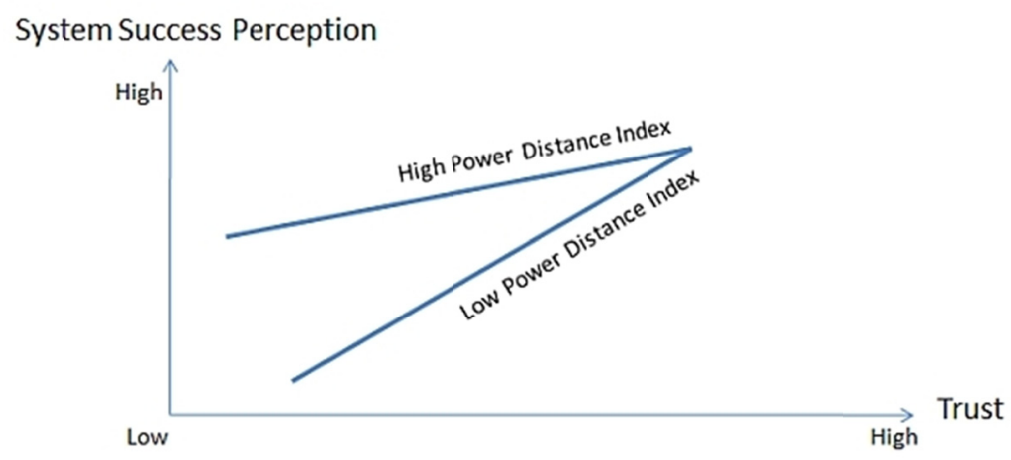

Figure 2. Hypothesized Interaction between CMMI and PDI

Identification of appropriate influencing factors and their impact on relational management can help further the IS field's understanding of relational management's effectiveness in IT outsourcing projects. The manner in which the attributes of these variables strengthen or attenuate the impact of relational management on perceived project outcome is useful knowledge for the IT field. It is possible that relational management is only useful to those with low PDI than those with high PDI. IT outsourcing literature has almost uniformly credited the relational management of projects with positive outcomes. However, positive outcomes from relational management may not be a foregone conclusion, it is entirely possible that the impact of relational management on project success perceptions is likely to vary as a function of the attributes of the contextual factors, such as PDI, that influence most IT outsourcing projects.

\section{Hypothesis}

\subsection{Hypothesis 1}

To reiterate, previous research has identified trust among stakeholders as a key success factor in outsourced information systems projects (Lander et al., 2004). Relational management is predicated on the existence of trust between interacting partners. In this study the interacting partners are the users and the vendor. A client who outsources IT software development to an external vendor is in a vulnerable situation because it has limited control over the vendor (Aron, Clemons, \& Reddi, 2005). Legal contracts and regulatory frameworks offer protection; however, they cannot cover the entire gamut of threats faced by the client (Hart, 1989). From an agency perspective, the vulnerability of the client is increased by adverse selection risk (Snir \& Hitt, 2004), which in this case is depending on an unreliable vendor (Gefen et al., 2008). Thus, the client is essentially vulnerable to the vendor's actions, which could jeopardize the successful completion of the project. Despite the presence of vulnerability, trust signals the willingness to depend on the interacting partner (Luhmann 1979, Gefen, 2000). Hence, the presence of trust between the users and the vendor would signify that the users are likely to believe in the integrity, benevolence, and capability of the vendor. A trusting user is likely to develop confidence in the vendor's motives and future behavior and is willing to rely on that vendor in situations that are potentially risky to the user (Doney et al., 1998). Such a user is more likely to be optimistic about the outcome of the project because trust mitigates perceptions of opportunistic behavior between the outsourcing vendor and the client (Nelson \& Cooprider, 1996; Sabherwal, 1999). Therefore, presence of trust could lead to interacting parties relying on cooperation and collaboration beyond merely a system of formal rules and legal norms 
(Bekmamedova, Pranato, McKay, \& Vorobiev, 2008).

Accordingly, in situations of trust based relational management, users are likely to believe that the system will be developed in accordance with mutually agreed principles and with the required functionality and quality expected by the users. Users are more likely to accept such a system. In situations where trust is lacking, users are less likely to believe that the vendor will abide by its promises and obligations. Hence, in such a situation, the users' perception of system success is likely to be low. Even though most IT relationships are built around formal contracts to anticipate contingencies, to achieve a win-win relationship both parties must operate with a spirit that eschews opportunistic behavior (Bekmamedova et al., 2008; Kern, 1997; Lacity \& Wilcox, 1993).

Accordingly,

Hypothesis 1: Trust between user and the vendor will be positively related to users' perceptions of system success.

\subsection{Hypothesis 2}

To summarize the implications from the cultural perspective, it is hypothesized in this study that in situations where user subscribes to high power-distance values, increased trust between the user and the vendor might lead to greater system-success perceptions for the user. However, in situations where users subscribe to low power-distance values, an increase in trust was expected to lead to much superior system-success perceptions as compared to a high power-distance user. This assertion acknowledges that high power-distance values induce individuals to believe in the efficacy of power over cooperative relationships (Hofstede, 1980). The need for trust is not felt as much as in low power-distance situations. A user subscribing to high power-distance values is likely to perceive the vendor as someone who can be managed more effectively through commands, contractual clauses, and threats of punitive action. Any increased perceived trust toward the vendor will likely be redundant to a high power-distance-values user. A user subscribing to low power distance, on the other hand, is more likely to appreciate a trusting, cooperative relationship with the vendor (Hofstede, 2001; Kaasa \& Vadi, 2008). Such a user is more likely to believe in managing the relationship with the vendor on the basis of trust, such that both parties engage in a transparent, honest relationship for mutual benefit and not in a relationship based on zero-sum game. Thus, in situations of relational management, the impact of trust on system success perceptions will be greater for users with low PDI than for users with a high PDI.

Hypothesis 2: The PDI of user will moderate the relationship between user vendor trust and user's system-success perceptions.

\section{Data Collection and Analysis}

\subsection{Data}

Data were collected through a questionnaire developed specifically for the present study. This study used a cross-sectional design to analyze data. An online survey was used to collect data from respondents. The items on the questionnaire were based on established instruments suitably modified for this study. The questionnaire was pretested for reliability and validity. The finalized questionnaire was then administered online to IT executives involved in IT outsourcing operations in their organizations. The contact information of such executives was obtained from multiple sources. The respondents were required to have either worked on an IT outsourcing survey in the past or be participating in an ongoing IT outsourcing project. The users' responses were analyzed through regression and interpreted for theoretical and practical implications. A total of 109 usable responses were collected out of over 350 total responses received.

The majority of respondents in the survey were men $(83.2 \%)$ and the remaining (14.9\%) were women. Regarding IT experience, $73.3 \%$ of respondents had over 9 years' experience and the remaining respondents had fewer than 9 years' experience, with two missing cases. Regarding outsourcing experience, $31.7 \%$ had over 9 years' experience, $13.9 \%$ had 7 to 9 years' experience, $14.9 \%$ had 4 to 6 years' experience, $23.8 \%$ had 1 to 3 years' experience, and $13.9 \%$ had less than 1 year of experience. Regarding organization size, $37.6 \%$ worked in organizations with 1,000 or more employees, $12.9 \%$ worked in organizations with 500 to 999 employees, $17.8 \%$ worked in organizations with 100 to 499 employees, and the rest worked in organizations with fewer than 100 employees.

\subsection{Analysis}

The data were collected separately for respondents currently engaged in IT outsourcing and respondents experienced but not currently engaged in outsourcing, therefore a MANOVA test was conducted to investigate whether the two separate groups could be combined in a single group for further analysis. For the MANOVA test, 
all variables from the two groups were entered, and no significant differences were found. As a result, the two groups were combined into one common data set. A demographic MANOVA was also conducted to examine whether the two groups were homogenous in terms of demographic attributes. The differences were not significant for age, race, gender, educational background, and total experience. A nonresponse test (MANOVA) was performed to compare the first 20 responses with the last 20 responses, and the differences were not significant.

For common method variance Hartman's single-factor test was performed. Only one single factor was extracted, without any rotation. The percentage of variance explained by this single factor was only $32 \%$, which is less than the commonly accepted cut off level of 50\%. Accordingly, common-method variance was not a major issue in this study. Multicollinearity tests were performed on the collected data and were found to be acceptable, meaning that no significant multicollinearity issues were found with the data. Cronbach's alpha for the entire data set was found to be 0.917 , revealing high reliability of the data set. A reliability analysis was performed on individual construct items as well and was found to be 0.745 and above.

Table 1 . Reliability measures

\begin{tabular}{ll}
\hline Scale & Cronbach's alpha \\
\hline Trust scale & 0.846 \\
Power-distance scale & 0.745 \\
System-success scale & 0.780 \\
\hline
\end{tabular}

An exploratory factor analysis was performed to determine how the items loaded on different factors. Any item that loaded at .40 on more than one factor or loaded on the wrong dimension was removed. The appropriate dimension selection was driven by judgment of where most items of that scale loaded. If any item of a scale loaded above 0.40 on a dimension that was not the dimension where most items of that scale had loaded, that item was removed from the scale. The only exception to this rule was to include two items in the trust scale, capability (capab1), which loaded at .438 on another factor, and competence (compet1), which loaded at .437 on another factor. This was done so that the trust scale would not be reduced to a single-item scale and because there is strong theoretical support for these items being related to trust

Table 2. Trust Instruments

\begin{tabular}{|c|c|c|}
\hline Question number & $\begin{array}{l}\text { Factor } \\
\text { loading }\end{array}$ & $\begin{array}{l}\text { Retained/ } \\
\text { dropped }\end{array}$ \\
\hline 1. Vendor is honest about its problems & 0.343 & Dropped \\
\hline 2. Vendor is capable ${ }^{*}$ & 0.571 & Retained \\
\hline 3. Vendor is frank with us in its dealings & 0.265 & Dropped \\
\hline 4. My organization can count on the vendor to be sincere & 0.391 & Dropped \\
\hline 5. Vendor is knowledgeable concerning their product & 0.754 & Retained \\
\hline 6. Vendor put our interest before its own & 0.014 & Dropped \\
\hline 7. Vendor is open in dealing with us & 0.315 & Dropped \\
\hline 8. Vendor is competent in its field* & 0.608 & Retained \\
\hline 9. Vendor cares about its customers & 0.364 & Dropped \\
\hline
\end{tabular}

Note. Based on Gefen (2002) and Gefen et al. (2003).

* Items were dropped if they loaded at 0.40 on more than one factor or loaded on the wrong factor. The only exceptions are item 2 and item 8 in the trust scale due to theoretical reasons and to ensure that the scale did not consist of just one item. 
Table 3. Power distance instrument

\begin{tabular}{|c|c|c|c|}
\hline \multicolumn{2}{|c|}{ Question number } & \multirow{2}{*}{$\begin{array}{l}\text { Factor } \\
\text { loading } \\
0.603\end{array}$} & \multirow{2}{*}{$\begin{array}{l}\text { Retained/ } \\
\text { dropped } \\
\text { Dropped }\end{array}$} \\
\hline 1. & Outsourcing organization should make most decisions without consulting vendor & & \\
\hline & $\begin{array}{l}\text { It is frequently necessary for the outsourcing organization to use authority and power when } \\
\mathrm{g} \text { with vendor }\end{array}$ & 0.574 & Dropped \\
\hline 3. & Outsourcing organization should seldom ask for the opinions of vendor & 0.723 & Retained \\
\hline 4. & Vendor should not disagree with outsourcing organization's decisions & 0.871 & Retained \\
\hline 5. & Outsourcing organization should not delegate important tasks to vendor & 0.802 & Retained \\
\hline
\end{tabular}

Note. Based on Dorfman and Howell (1988).

Table 4. System-Success perception

\begin{tabular}{llll}
\hline Question number & Factor loading & Retained/ dropped \\
\hline 1. & I will use the system frequently & 0.782 & Retained \\
2. & The system should be useful to my work & 0.785 & Retained \\
3. & If the system use was not mandatory, I will still use the system & 0.577 & Retained \\
4. & The system functionality will meet my work requirements adequately & 0.740 & Retained \\
5. & I will be satisfied with the system & 0.682 & Dropped \\
6. & The system is likely to be built within allotted time & 0.284 & Dropped \\
7. & The system is likely to be built within allotted budget & 0.288 & Dropped \\
\hline
\end{tabular}

Note. Based on Saarinen (1996) and Seddon and Kiew (1996).

Regression tests were conducted to test the two hypotheses proposed in this study.

Table 5. Descriptive Statistics: Items

\begin{tabular}{lccc}
\hline & $M$ & $S D$ & $N$ \\
\hline Trust & 3.7976 & 0.78624 & 107 \\
PowerDist & 2.7170 & 0.81491 & 106 \\
SysSuccess & 3.6262 & 0.71323 & 107 \\
\hline
\end{tabular}

Table 6A. Relationship between trust and system success, moderated by power distance

\begin{tabular}{|c|c|c|c|c|c|c|}
\hline \multirow{2}{*}{\multicolumn{2}{|c|}{ Model }} & \multicolumn{2}{|c|}{ Unstandardized coefficients } & \multirow{2}{*}{$\begin{array}{l}\text { Standardized coefficients } \\
\beta\end{array}$} & \multirow[b]{2}{*}{$t$} & \multirow[b]{2}{*}{ Sig. } \\
\hline & & $\beta$ & $S E$ & & & \\
\hline 1 & (Constant) & 1.665 & 0.353 & & 4.720 & $<0.001$ \\
\hline \multirow{6}{*}{2} & Trust & 0.367 & 0.080 & 0.400 & 4.579 & $<0.001$ \\
\hline & PowerDist & 0.205 & 0.075 & 0.238 & 2.729 & 0.008 \\
\hline & (Constant) & 1.810 & 0.359 & & 5.048 & $<0.001$ \\
\hline & Trust & 0.311 & 0.085 & 0.340 & 3.653 & $<0.001$ \\
\hline & PowerDist & 0.234 & 0.076 & 0.271 & 3.066 & 0.003 \\
\hline & TrustPowerDist & -.093 & .053 & -.166 & -1.771 & .080 \\
\hline
\end{tabular}

Table 6B. Model Summary

\begin{tabular}{llllllllll}
\hline & & & & \multicolumn{9}{l}{ Change Statistics } \\
\cline { 6 - 9 } Model & $R$ & $R^{2}$ & Adj. $R^{2}$ & $S E$ of estimate & $R^{2}$ change & $F$ change & $d f 1$ & $d f 2$ & Sig. $F$ change \\
\hline 1 & 0.488 & 0.238 & 0.223 & 0.62395 & 0.238 & 15.796 & 2 & 101 & 0.000 \\
2 & 0.511 & 00.261 & 0.239 & 0.61745 & 0.023 & 3.138 & 1 & 100 & 0.080 \\
\hline
\end{tabular}


Table 7. Summary of results

\begin{tabular}{lll}
\hline Hypothesis & Result \\
\hline 1. & Power distance index will moderate the relationship between trust and system-success perceptions & Not supported \\
2. & Trust between user and vendor will be positively related to his/her perceptions of system success & Supported \\
\hline
\end{tabular}

Below the results of the analysis are discussed.

\section{Discussion of Results}

\subsection{Hypothesis 1}

Hypothesis 1 stated that trust in the vendor would lead to user system-success perceptions. This hypothesis was supported. Trust in the vendor was instrumental in generating system success perceptions among users.

\subsubsection{Implications}

The results indicate that trust was positively related to system-success perceptions among users. As hypothesized, trust between the user and the vendor did likely develop users' confidence in the vendor's motives and behaviors, thereby encouraging users to rely on that vendor to do a good job. Trust also likely mitigated perceptions of opportunistic behavior between the vendor and the user (Nelson \& Cooprider, 1996; Sabherwal, 1999). Instead of relying solely on contract-based management of the project, users were likely encouraged by the trust in vendor to expect successful completion of the project.

\subsection{Hypothesis 2}

Hypothesis 2 stated that PDI would moderate the relationship between user-vendor trust and users' system-success perceptions. This hypothesis was not supported $(p=.08)$. This study hypothesized that a user who subscribes to high power-distance cultural values will not place much importance on trust as much as a user who subscribes to low power-distance cultural values. This is because subscribers to high power-distance culture will likely be more inclined to a command and control kind of interaction in which relationships are based more on the ability to apply punitive action rather than foster trust. Subscribers to low power-distance values are more likely to adopt a trust-based interaction because, for them, formal contractual clauses are more of a backup rather than the primary means of ensuring performance. As shown by the results of this study, power-distance values did not interact with the relationship between trust and system-success perceptions.

\subsubsection{Implications}

In this study, the cultural context, or power-distance values, did not affect the respondents' perceptions of system success. System-success perceptions of respondents with high or low power-distance values were not significantly different from each other in situations of high or low trust. This result implies that, in an IT outsourcing situation, when dealing with the outside vendor, users do not allow their relation to authority ideology to affect the business transaction they are engaged in. That trust did not interact with power-distance values indicates that users with low power-distance values did not value trust over command- and control-type behavior when it came to dealings with the vendor and users with high power distance values did not under appreciate role of trust in their interactions with the vendor.

\section{Contribution of the Study}

Of the two hypotheses tested by this study, one was supported and one was not supported. Trust between user and vendor, indicating presence of relational management, was found to be positively related to users' system-success perceptions. Researchers have advocated the complementary governance approach using an optimal combination of relational and contractual governance mechanisms to attain project success (Goo \& Nam, 2007; Poppo \& Zenger, 2002). Trust based relational management can thus be considered an important complement to contractual governance, strengthening the relationship between the user and the vendor by adding an extra layer of confidence.

The results of this study can be used to help improve client-vendor relationship in IT outsourcing projects by creating an atmosphere of mutual cooperation and trust to add the relational component to the formal contractual governance mechanism. Combination of contractual and relational governance can in turn help projects run more smoothly and increase the perception of successful outcomes, thereby improving morale, help fill in the gaps in contractual stipulations and achieve superior overall interaction between the two parties. The relational management perspective emphasizes flexibility, solidarity, and information exchange to safeguard against 
exchange hazards and facilitate the enforcement of mutual obligations (Baker, Gibbons, \& Murphy, 2002; Zheng, Roehrich, \& Lewis, 2008). Especially useful against unforeseen contingencies that may or may not be covered by contractual clauses, relational management provides backup to ties with the vendor in a project (Zheng et al., 2008).

PDI did not influence trust's role in the formation of system-success perceptions in this study. This result could be interpreted to mean that the power-distance values of the users are not likely to interfere with the relational management of the project. A user with high power-distance values is unlikely to underrate the role of trust simply because he is inherently inclined to believe in a command and control mechanism for managing client-vendor relationships. A user with low power-distance values is also unlikely to believe in trust being more effective in comparison to the contractual management of the project. Because users' power-distance values did not affect trust's influence on their system-success perceptions, it may be surmised that users did not perceive their relationships with vendors through the prism of relative power equation. In this study, relationship asymmetry between the user and the vendor was not investigated; hence, it is not exactly clear if the user perceived the vendor as wielding superior or inferior power in the business relationship.

Regarding the implications of the results for practitioners, one of the critical factors in attaining success in global outsourcing activities is the quality of the user-vendor relationship (Oshri et al., 2009). Transparency and integrity in reporting project metrics, quality of coding, careful design, fair and reasonable change management process and timely payments are some of the key issues that can decide the quality of client-vendor interactions (Oshri et al., 2009). Robust change-control processes to keep effective accounting of cost certainly helps, but with trust, the long-term perspective dominates over short-term issues. It is often the case that contracting parties usually find it impossible to lay out clear-cut obligations and deliverables at the outset. Trust enables them to focus on important issues rather than expend resources on auditing and verifying each other at every step. Since no project can be designed with every contingency accounted for at the very beginning and listed in contractual stipulations, relational management provides the critical backup support to formal governance and successful completion of a project.

\section{Limitations of This Study}

The cross-sectional design of this study is a limitation because it could have allowed selection bias and only provides a snapshot at one point in time, thereby making temporal associations unclear. Causality is difficult to assess through such studies (Hoyle et al., 2002). While due care was taken to inform respondents of the outsourcing experience needed to participate in the survey; however, it was not possible to deter those who might be lacking in such experience given the study used an online survey.

\section{Future Research}

Relational management is an important addition to routine formal governance mechanism. The interplay between the two governance mechanisms, relational and contractual, is important in the context of Western organizational philosophy which rates contracts highly. Development of a combined governing strategy to manage IT outsourcing projects can further improve their management; however, more research is needed to arrive at the optimal combination of relational and contractual governance. While role of trust based relational management is clearly important to successful IT project management, how much faith parties can place in relational management is as yet an open question. Further research can help clear up this issue.

\section{References}

Aron, R., Clemons, E. K., \& Reddi, S. (2005). Just right outsourcing: Understanding and managing risk. Journal of Management Information Systems, 22(2), 37-55. https://doi.org/10.1080/07421222.2005.11045852

Baker, G., Gibbons, R., \& Murphy, K. J. (2002). Relational Contracts and the Theory of the Firm. The Quarterly Journal of Economics, 117(1), 39-84. https://doi.org/10.1162/003355302753399445

Bekmamedova, N., Prananto, A., McKay, J., \& Vorobiev, A. (2008). Towards better understanding of the relationship between formal controls and trust in IS outsourcing. ACIS 2008 Proceedings, Paper 53. Retrieved from http://aisel.aisnet.org/acis2008/53

Carmel, E., \& Agarwal, R. (2002). The maturation of offshore sourcing of information technology work. MIS Quarterly Executive, 1(2), 65-77.

Clark, T. (1990). International marketing and national character: A review and proposal for an integrative theory. Journal of Marketing, 54(4), 66-79. https://doi.org/10.2307/1251760 
Dibbern, J., Winkler, J., \& Heinzl, A. (2008). Explaining variations in client extra costs between software projects to India. MIS Quarterly, 32(2), 333-366.

Doney, P. M., Cannon, J. P., \& Mullen, M. R. (1998). Understanding the influence of national culture on the development of trust. Academy of management Review, 23(3), 601-620.

Ford, D. P., Connelly, C. E., \& Meister, D. B. (2003). Information systems research and Hofstede's Culture's Consequerces: An uneasy and incomplete partnership. IEEE Transactions on Engineering Management, 50(1), 8-25. https://doi.org/10.1109/TEM.2002.808265

Fukuyama, F. (1995). Trust: The social virtues and creation of prosperity. New York, NY: Free Press.

Gartner Research. (2007). Gartner on Outsourcing 2007-2008: Business Process Outsourcing.

Gefen, D. (2000). E-Commerce. The role of familiarity and trust. Omega, 28(6), 725-737. https://doi.org/10.1016/S0305-0483(00)00021-9

Gefen, D. (2004). What makes an ERP implementation relationship worthwhile: Linking trust mechanisms and ERP usefulness. Journal of Management Information Systems, 21(1), 263-288. https://doi.org/10.1080/07421222.2004.11045792

Gefen, D., \& Heart, T. (2006). On the need to include national culture as a central issue in e-commerce trust beliefs.

Gefen, D., Wyss, S., \& Lichtenstein, Y. (2008). Business familiarity as risk mitigation in software development outsourcing contracts. MIS Quarterly, 32(3), 531-551.

Goo, J., Kishore, R., Rao, H. R., \& Nam, K. (2009). The role of service level agreements in relational management of information technology outsourcing: An empirical study. MIS Quarterly, 33(1), 119-145.

Goo, J. \& Nam, K. (2007). Contract as a Source of Trust - Commitment in Successful IT Outsourcing Relationship: An Empirical Study. Proceedings of the 40th Annual Hawaii International Conference on System Sciences (HICSS'07). https://doi.org/10.1109/hicss.2007.148

Hart, O. D. (1989). An economist's perspective on the theory of the firm. Columbia Law Review, 89(7), 1757-1774. https://doi.org/10.2307/1122818

Hofstede, G. (1980). Culture's consequences: International differences in work related values. Newbury Park, CA: Sage.

Hofstede, G. (1984). Culture's consequences: International differences in work related values. Newbury Park, CA: Sage.

Hofstede, G. (2001). Culture's consequences: Comparing values, behaviors, institutions and organizations across nations. Newbury Park, CA: Sage.

Hofstede, G., Jonker, C. M., \& Verwaart, T. (2008). Modeling power distance in trade. 9th International workshop on Multi-Agent Based Simulation at AAMAS, Estoril, Portugal.

Hosmer, L. T. (1995). Trust: The connecting link between organizational theory and philosophical ethics. Academy of Management Review, 20(2), 379-403.

Hoyle, R. H., Harris, M. J., \& Judd, C. M. (2002). Research methods in social relations. Florence, KY: Wadsworth.

Kaasa, A, Vadi, M. (2008). How Does Culture Contribute To Innovation? Evidence from European Countries. The University of Tartu Faculty of Economics and Business Administration Working Paper No. 63-2008. https://doi.org/10.2139/ssrn.1268359

Kadefors, A. (2004). Trust in project relationships: Inside the black box. International Journal of Project Management, 22(3), 175-182. https://doi.org/10.1016/S0263-7863(03)00031-0

Kern, T. (1997). The gestalt of an information technology outsourcing relationships: An explanatory analysis. Proceedings of the 18th International Conference on Information Systems, 37-58.

Lacity, M. C., \& Hirschheim, R. (1993). Information systems outsourcing: Myths, metaphors, and realities. Chichester, UK: Wiley.

Lacity, M. C., \& Willcocks, L. P. (1998). An empirical investigation of information technology sourcing practices: Lessons from experience. MIS Quarterly, 17(1), 363-308. https://doi.org/10.2307/249670 
Lander, M. C., Purvis, R. L., McCray, G. E., Leigh, W. (2004). Trust-building mechanisms utilized in outsourced IS development projects: A case study. Information \& Management, 41(4), 509-528. https://doi.org/10.1016/j.im.2003.10.001

Luhmann, N. (1979). Trust and power. Chichester, England: Wiley.

Luhmann, N. (1988). Familiarity, confidence, trust: Problems and alternatives. In D. Gambetta (Ed.), Trust (pp. 94-107). New York, NY: Basil Blackwell.

MacNeil, I. R. (1980). The new social contract: An inquiry into modern contractual relations. New Haven, CT: Yale University Press.

Mayer, R. C., Davis, J. H., \& Schoorman, F. D. (1995). An integrative model of trust. Academy of Management Review, 20(3), 709-734.

McEvily, B., Perrone, V., \& Zaheer, A. (2003). Trust as an organizing principle. Organization Science, 14(1), 91-103. https://doi.org/10.1287/orsc.14.1.91.12814

McDougall, P. (2006). Dexterity required. InformationWeek, 19, 34-39.

Nasierowski, W., \& Mikula, B. (1998). Culture dimensions of Polish managers: Hofstede's indices. Organization Studies, 19(3), 495-509. https://doi.org/10.1177/017084069801900306

Nelson, K. M., \& Cooprider, J. G. (1996). The contribution of shared Knowledge to IS group performance. MIS Quarterly, 20(4), 409-432. https://doi.org/10.2307/249562

Oshri, I., Kotlarsky, J., \& Willcocks, L. P. (2009). The handbook of global outsourcing and offshoring. New York, NY: Palgrave MacMillan. https://doi.org/10.1057/9780230251076

Poppo L., \& Zenger, T. R. (2002). Do formal contracts and relational governance function as substitutes or complements? Strategic Management Journal, 23(8), 707-725. https://doi.org/10.1002/smj.249

Rai, A., Maruping, L. M., \& Venkatesh, V. (2009). Offshore information systems project success: The role of social embeddedness and cultural characteristics. MIS Quarterly, 33(3), 617-641.

Rustagi, S., King, W. R., \& Kirsch, L. J. (2008). Predictors of formal control usage in IT outsourcing partnerships. Information Systems Research, 19(2), 126-143. https://doi.org/10.1287/isre.1080.0169

Sabherwal, R. (1999). The role of trust in outsourced IS development projects. Communications of the ACM, 42(2), 80-86. https://doi.org/10.1145/293411.293485

Shaffer, T. R., \& O'Hara, B.S. (1995). The Effects of Country of Origin on Trust and Ethical Perceptions of Legal Services. The Service Industries Journal, 15(20), 162-185. https://doi.org/10.1080/02642069500000019

Simon, H. A. (1957). Models of man: Social and rational. New York, NY: Wiley.

Snir, E. M., \& Hitt, L. M. (2004). Vendor screening in information technology contracting with a pilot project. Journal of Organizational Computing and Electronic Commerce, 14(1), 61-88. https://doi.org/10.1207/s15327744joce1401_4

Statista.com (2015). http://www.statista.com/statistics/298554/global-spending-it-outsourcing-market

Tirole J. (2007). Bounded rationality and incomplete contracts. Working Paper IDEI, Université de Toulouse.

Volkema, R. J. (2004). Demographic, cultural, and economic predictors of perceived ethicality of negotiation behavior: a nine country analysis. Journal of Business Research, 57(1), 69-78. https://doi.org/10.1016/S0148-2963(02)00286-2

Williamson, O. (1985). The economic institutions of capitalism. New York, NY: Free Press.

Zheng J., Roehrich J. K., \& Lewis, M. A. (2008). The dynamics of contractual and relational governance: Evidence from long-term public-private procurement arrangements. Journal of Purchasing and Supply Management, 14(1), 43-54. https://doi.org/10.1016/j.pursup.2008.01.004

\section{Copyrights}

Copyright for this article is retained by the author(s), with first publication rights granted to the journal.

This is an open-access article distributed under the terms and conditions of the Creative Commons Attribution license (http://creativecommons.org/licenses/by/4.0/). 